\title{
Urinary 3-hydroxyproline excretion in Alport's syndrome: a non-invasive screening test?
}

\author{
B Bartosch, W Vycudilik, C Popow, G Lubec
}

\begin{abstract}
Alport's syndrome is characterised by morphological and structural changes of the renal basement membranes. As the hydroxyproline content of isolated glomerular basement membranes is reduced in patients with Alport's syndrome, it is possible that the renal excretion of 3-hydroxyproline (3-OHP), a key substrate of basement membrane collagen, may be altered in such patients. The urinary excretion of 3-OHP was determined by thin layer chromatography in 20 patients with Alport's syndrome, in healthy control subjects, and in patients with other renal diseases. These included patients with poststreptococcal glomerulonephritis, lower urinary tract infection, severe reflux nephropathy, lithium induced nephropathy, polycystic kidney disease, familiar benign haematuria, and renal graft rejection. Urinary excretion of 3-OHP was significantly higher in patients with Alport's syndrome compared with the patients with other renal diseases and the healthy control subjects. All other renal diseases investigated had 3-OHP values within the normal range. Urinary 3-OHP determination detected patients with Alport's syndrome with a high sensitivity $(95.2 \%)$ and specificity $(97 \cdot 2 \%)$. We therefore suggest using urinary 3-OHP determinations as a simple non-invasive screening test for Alport's syndrome.
\end{abstract}

Alport's syndrome, a hereditary disorder, is characterised by morphological and structural changes of the renal basement membranes. Morphologically, electron lucent and electron dense areas, cloudy networks, fraying, splitting, thickening, distortion, and thinning of the lamina densa may be observed by electron microscopy. ${ }^{1}$ However, the underlying mechanisms and molecular defects of the disease are still unclear.

Collagen type IV, an integral component of the glomerular basement membrane, ${ }^{2}$ is immunologically different in patients with Alport's syndrome compared with healthy subjects. $^{3-5}$ Hydroxyproline, a major constituent of collagens, was reported to be reduced in isolated glomerular basement membranes of patients with Alport's syndrome. ${ }^{6}$ Hydroxyproline exists in two stereoisomeric 'trans' forms: 4trans-hydroxyproline (4-OHP) and 3-transhydroxyproline (3-OHP) but, unlike other connective tissue collagens, basement membranes normally contain large amounts of $3-\mathrm{OHP}{ }^{7}$ As 3-OHP is excreted with the urine, changes in the collagen metabolism of the renal basement membranes could be reflected by a different urinary excretion of 3-OHP.

In order to test this hypothesis, and to find out characteristic differences, we studied the urinary excretion of 3-OHP in patients with Alport's syndrome, in healthy control subjects, and in patients with other renal diseases.

\section{Patients and methods}

Urine samples of 20 patients with Alport's syndrome were obtained from Sint Radboudziekenhuis, Institute foor Kindergeneeskunde, Nijmegen, The Netherlands. The median age of these patients was 16 years (range 4 days-57 years). There were 15 females and five males. The diagnosis was confirmed by the presence of albuminuria (20/20), by familial history (18/20), and/or by electron microscopy (10/20).

There were two groups of control subjects. The first group consisted of healthy control subjects and comprised 23 newborn infants (age 230 days), 11 infants (age 1-12 months), 16 toddlers (age $1-4$ years), 47 children and adolescents (age 8-18 years), and 12 adults (age 22-41 years). The second group consisted of subjects with other renal diseases and comprised 10 children with acute and 10 children with chronic poststreptococcal glomerulonephritis, 10 children with haemorrhagic lower urinary tract infection, 10 children with severe reflux nephropathy (reflux grade 4), 10 adults with lithium nephropathy, five children with adult type polycystic kidney disease, seven children with familiar benign haematuria, and five children with acute renal graft rejection (10 urine samples). Urine samples consisted of spontaneously voided urine or of aliquots of a 24 hour collection period.

We determined the type of proteinuria (high/ low molecular weight proteinuria) by polyacrylamide gel electrophoresis (PAGE) of the urine samples from the patients with Alport's syndrome. PAGE was performed according to standard principles using $8 \%$ polyacrylamide gel, molecular weight markers, and staining with coomassie blue.

The urinary concentration of 3-OHP was determined by thin layer chromatography. Urine samples were centrifuged at $3000 \mathrm{~g}$ for five minutes at room temperature and the supernatant used. The urinary volume used for chromatography was determined according to its creatinine content, which was analysed by Jaffé's method (Astra Beckman (R) Automatic Analyzer, Beckman). The volume containing 1 mg creatinine was added to $1 \mathrm{ml}$ of $0.1 \mathrm{M}$ phosphate buffer, $\mathrm{pH} 7 \cdot 0$, and $1 \mathrm{mg}$ of charcoal
Correspondence to: Dr Lubec.

Accepted 10 August 1990 
(Sigma C 5385). This mixture was vortexed for 20 seconds and centrifuged at $2000 \mathrm{~g}$ for 10 minutes at room temperature. The pellet was resuspended in $1 \mathrm{ml}$ of $0.1 \mathrm{M}$ phosphate buffer, $\mathrm{pH} 7 \cdot 0$, centrifuged again at $2000 \mathrm{~g}$ for 10 minutes. The pooled supernatants were applied to columns containing $3 \mathrm{ml}$ of Dowex $50 \mathrm{~W}$ X 8 (Bio Rad 745-6441), 100-200 mesh, in hydrogen form. Amino acids were eluted with $2 \mathrm{ml}$ of $4 \mathrm{M}$ ammonia. The eluate was evaporated until dryness on a Pierce Reactitherm Heating Module and redissolved in $200 \mu \mathrm{l}$ distilled water. An aliquot of $100 \mu$ lof this solution was added to 20 $\mu l$ o-phthalaldehyde (30\% triethylamine, $70 \%$ ethanol, $8 \mathrm{mg} / \mathrm{ml}$, Pierce $26 \cdot 010$ ). The mixture was incubated at room temperature in the dark for 30 minutes and then evaporated until dryness. The samples were redissolved in $20 \mu \mathrm{l} 0 \cdot 1$ $\mathrm{M}$ phosphate buffer $\mathrm{pH} 7 \cdot 0$. Adding $20 \mu \mathrm{l} 7$ chloro-4-nitrobenz-2-oxa-1,3 diazole $(8 \mathrm{mg}$ dissolved in $1 \mathrm{ml}$ ethanol), the samples were heated in a waterbath for 10 minutes at $40^{\circ} \mathrm{C}$. The samples were spun for 5 minutes at $2000 \mathrm{~g}$. Ten $\mu \mathrm{l}$ of the resulting supernatant were applied to HP thin layer chromatography plates (LHP-KF Whatman 4806). The development solution consisted of acetone:chloroform:methanol: triethylamine $=20: 60: 12 \cdot 5: 7 \cdot 5)$. The plates were read at $365 \mathrm{~nm}$ on a Shimadzu TLC scanner CS 920; 4-trans-hydroxyproline (Sigma H 60.002), 4-cis-hydroxyproline (Sigma H 1.637), 3-transhydroxyproline, and 3-cis-hydroxyproline (synthesised by $\mathrm{J}$ Häusler $^{8}$ ) were used as standards.

Specificity of the determinations on thin layer chromatography of 3-OHP was confirmed by high pressure liquid chromatography (HPLC) and by gas chromatography-mass spectrometry (GC-MS) in the standards used for the chromatography and in the urine samples obtained from the healthy adults. For the HPLC determinations checkpot samples, taken from the thin layer chromatography, were dissolved in elution buffer and characterised on reverse phase chromatography according to Lindblad and Diegelmann. ${ }^{9}$ For the GC-MS determinations N-trifluoroacetly-Otrimethylsilyl-hydroxyproline-trimethylsily-esters were prepared according to Donike, ${ }^{10}$ GC-MS determinations were performed on a Varian MAT 112 according to Vycudilik and Lubec. ${ }^{11}$ The hydroxyprolines were characterised by two techniques: (i) monitoring of the $\mathrm{M}-15$ fragment ion (m/e) 356, single ion monitoring (SIM) and (ii) analysis of the full mass spectra taken along with the GC separation of the derivatives at a rate of $1 \mathrm{sec} / \mathrm{mass}$ decade.

Differences between groups and within groups were analysed by the Kruskal-Wallis test. ${ }^{12}$ Sensitivity of the 3-OHP determinations for detecting Alport's syndrome was defined as the proportion of patients with Alport's syndrome having a 3-OHP value above the range of the mean +2 SD of the 3-OHP values of the normal control subjects. Specificity of $3-\mathrm{OHP}$ determinations for detecting Alport's syndrome was defined as the proportion of control subjects and of patients with other renal diseases having a 3-OHP value within the range of the mean and 2 SD of the normal control subjects.

\section{Results}

Polyacrylamide gel electrophoresis showed nonsignificant unspecific high molecular weight $(=$ glomerular) proteinuria in $12 / 20$ patients with Alport's syndrome.

Results of the thin layer chromatography determinations of 3-OHP are shown in the table and in fig 1 and 2. They were highly significant differences between the 3-OHP values of the patients with Alport's syndrome compared with the normal control subjects and with the patients with other renal diseases but no difference between the latter and the normal control subjects.

In a single patient with Alport's syndrome the 3-OHP excretion was within the normal range (mean, $2 \mathrm{SD}$ ) of the healthy control subjects, and five control subjects had a 3-OHP value above the 2 sigma range of the healthy control subjects. All patients with other renal diseases had 3-OHP values within the normal range. Thus a specificity of $97 \cdot 2 \%$ and a sensitivity of $95 \cdot 2 \%$ of the thin layer chromatography $3-\mathrm{OHP}$ determinations may be calculated for the patients with Alport's syndrome.

Results of the 3-OHP determinations

\begin{tabular}{|c|c|c|c|}
\hline \multirow[t]{2}{*}{ Group } & \multirow{2}{*}{$\begin{array}{l}\text { No of } \\
\text { subjects }\end{array}$} & \multicolumn{2}{|c|}{ Concentrations of $3-\mathrm{OHP}$} \\
\hline & & Mean $(S D)$ & Range \\
\hline Alport's syndrome & 21 & $5.64(2.43)^{*}$ & $+1 \cdot 97-10 \cdot 24$ \\
\hline $\begin{array}{l}\text { Normal controls: } \\
\text { Adults } \\
\text { Children } \\
\text { Infants } \\
\text { Newborns } \\
\text { Toddlers }\end{array}$ & $\begin{array}{r}98 \\
8 \\
40 \\
11 \\
23 \\
16\end{array}$ & $\begin{array}{l}0.96(0.59) \\
0.34(0.14) \\
1.08(0.40) \\
1.50(0.47) \\
0.36(0.13) \\
1.44(0.64)\end{array}$ & $\begin{array}{l}0.06-2 \cdot 55 \\
0.06-0.55 \\
0.52-2 \cdot 40 \\
0.91-2.55 \\
0.20-0.60 \\
0.32-2.34\end{array}$ \\
\hline $\begin{array}{l}\text { Other renal diseases: } \\
\text { Acute glomerulonephritis } \\
\text { Chronic glomerulonephritis } \\
\text { Urinary tract infection } \\
\text { Reflux nephropathy } \\
\text { Lithium nephropathy } \\
\text { Polycystic kidneys } \\
\text { Familiar benign haematuria } \\
\text { Graft rejection }\end{array}$ & $\begin{array}{r}82 \\
10 \\
10 \\
20 \\
10 \\
10 \\
5 \\
7 \\
10\end{array}$ & $\begin{array}{l}1.05(0.30) \\
0.94(0.22) \\
1.09(0.38) \\
0.96(0.21) \\
1.23(0.25) \\
0.98(0.29) \\
0.94(0.48) \\
1.24(0.30) \\
1.07(0.30)\end{array}$ & $\begin{array}{l}0 \cdot 41-2 \cdot 10 \\
0 \cdot 47-1 \cdot 21 \\
0 \cdot 74-2 \cdot 10 \\
0 \cdot 47-1 \cdot 43 \\
0 \cdot 72-1 \cdot 57 \\
0 \cdot 41-1 \cdot 33 \\
0 \cdot 53-1 \cdot 72 \\
0 \cdot 78-1 \cdot 74 \\
0 \cdot 54-1 \cdot 48\end{array}$ \\
\hline
\end{tabular}

*Significantly different from control group $(\mathbf{p}<0.0001)$. †Significantly different from other renal diseases group $(\mathbf{p}<0.0001)$

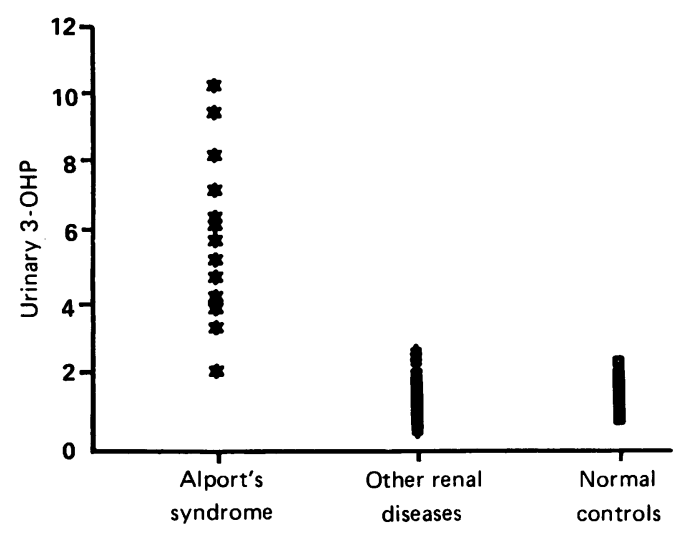

Figure 1 Determinations of 3-hydroxyproline (3-OHP) $\mu \mathrm{g} / \mathrm{mg}$ creatinine by thin layer chromatography in patients with Alport's syndrome $(n=20)$, patients with other renal diseases $(n=67)$, and normal control subjects $(n=109)$. 


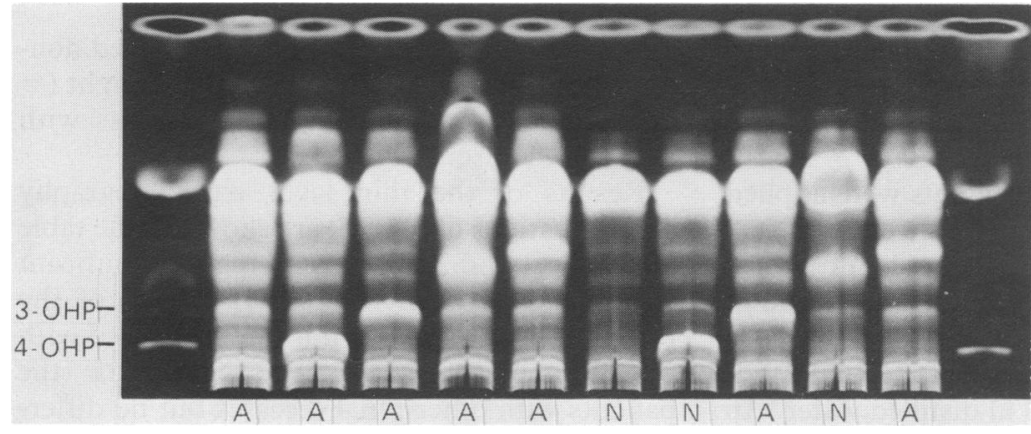

Figure 2 Thin layer chromatogram of 3-hydroxyproline (3-OHP) in patients with Alport's syndrome $(A)$, in normal control subjects $(N)$, and of hydroxyproline standards (4-UHP=4-trans-hydroxyproline).

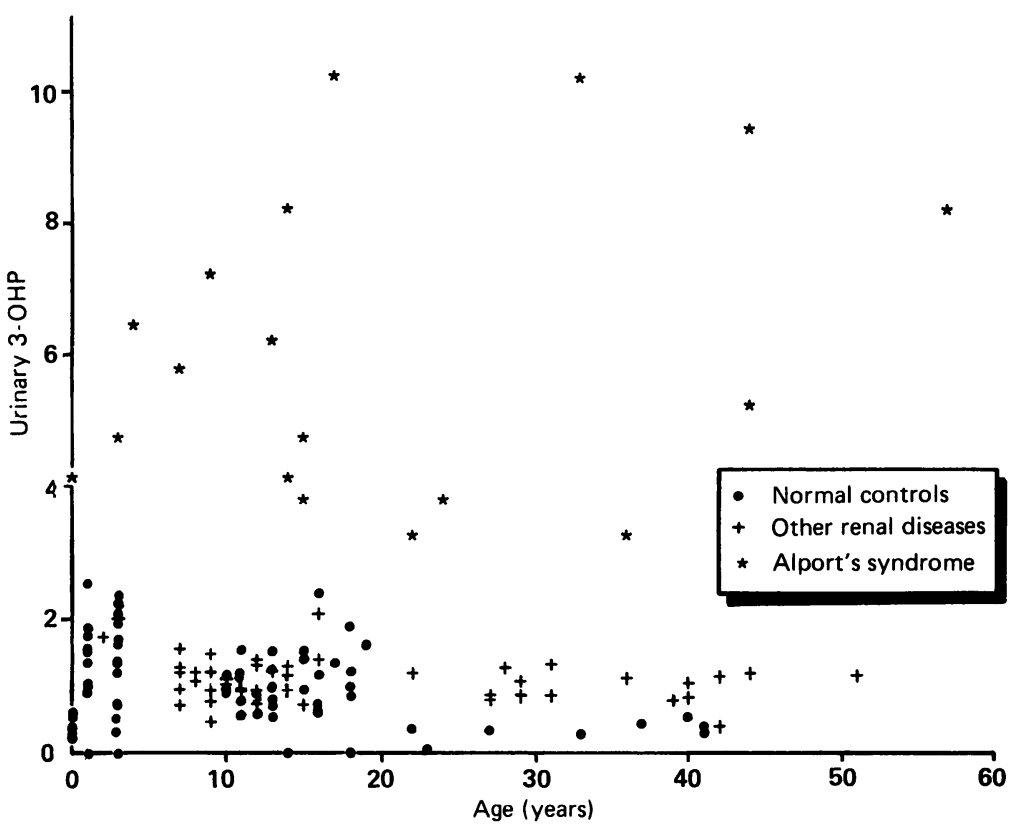

Figure 3 Relation between 3-hydroxyproline (3-OHP) $\mu \mathrm{g} / \mathrm{mg}$ creatinine and age of the patients with Alport's syndrome $(n=20)$, patients with other renal diseases $(n=67)$, and normal control subjects $(n=109)$. drome, in the normal controls, nor in the patients with other renal diseases (fig 3).

The identification of the 3-OHP bands by thin layer chromatography was confirmed by HPLC and GC-MS determination in all 12 urine samples investigated (fig 4).

\section{Discussion}

This is the first report about an increased excretion of 3-OHP in patients with Alport's syndrome. There are reports on differences of the excretion of other amino acids: Tina $e t a l^{6}$ and Veltischev $e t a l^{13}$ found an increased urinary excretion of glycosylated hydroxylysine, another amino acid which may be found in collagens of basement membranes in relatively low amounts. However, this was not confirmed by Schröder et al. ${ }^{14}$ Borel et al found an increased 3-OHP excretion in patients with other renal diseases-like glomerulonephritis-where proliferation and damage of the basement membranes are likely to occur. ${ }^{15}$ In the latter study the total concentration of 3-OHP was determined in samples of hydrolysed urine, however, whereas we determined the urinary concentration of free 3-OHP. Hydrolysis may also involve remnant cells, micro-organisms, and cell and other debris. Moreover, treatment with acids may cause isomerisation of trans hydroxyproline to its cis form and thus lead to erroneous results. ${ }^{16}$

HPLC and GC-MS determinations showed that the described method of thin layer chromatography accurately measured 3-OHP. We related the urinary 3-OHP concentration to the urinary creatinine excretion in order to rule out differences in renal clearance and to avoid long lasting urine collection periods. Although the urine samples of the patients with Alport's syndrome were transported frozen, we cannot rule out that freezing may have caused degradation processes. According to our experience, however, repeated freezing and thawing as well as temperature changes may result in rapid degradation of 3-OHP causing falsely decreased concentrations of 3-OHP, whereas we found raised concentrations of 3-OHP in the patients with Alport's syndrome.

The increased excretion of 3-OHP may possibly be explained as follow: after ribosomal translation of basement membrane collagen proteins, prolyl residues are subjected to the action of post-translational enzymes such as prolyl hydroxylase, lysyl hydroxylase, glycosly transferases, etc. There is a highly specific 3 and 4 prolyl hydroxylase acting only upon non-helical collagen proteins. Cross linking and helical formation of collagens are possibly disturbed in Alport's syndrome. ${ }^{17}$ Therefore non-helical collagens could be subjected to a prolonged action of post-translational enzymes, possibly preferably to 3-prolyl hydroxylase. This could lead to an increased excretion of 3-OHP whereas other basement membrane amino acids such as 4OHP and hydroxylysine would be excreted in normal amounts (see above).

The high specificity and sensitivity of the increased 3-OHP excretion in patients with Alport's syndrome suggest that the determination of 3-OHP could be helpful as a screening We found no correlation between age and 3 OHP values in the patients with Alport's syn- 
test for this disease, especially if the noninvasiveness, simplicity, and specificity of the method is taken into consideration. Further studies are needed to confirm its clinical relevance.

We are highly indebted to $\mathrm{Dr} \mathrm{J}$ Häusler, Institute of Organic Chemistry, University of Vienna, for the synthesis of the structural analogues. We also highly appreciate the excellent technical assistance of Dr M T Weiss and Mrs Dalisay Ronquillo.

1 Hinglais N, Grünfeld JP, Bois E. Characteristic ultrastructural lesions of the glomerular basement membrane in progressive hereditary glomerulonephritis (Alport's syndrome). Lab Invest 1972;27:473-81.

2 Lubec G. Definition of the glomerular basement membrane. Renal Physiol 1983;7:61-3.

3 McCoy RC, Johnson HK, Stone WH, Wislon CS. Absence of nephritogenic GBM antigen(s) in some patients with hereditary nephritis. Kidney Int 1982;21:642-7.

4 Lubec G, Chamdawallah S. Noninvasive diagnosis of Alport's syndrome. Lancet 1984;i:1119.

5 Di Bona GF. Alport's syndrome: a genetic defect in biochemical composition of basement membranes of glomerulus, lens and inner ear? Laboratory and Clinical Medicine 1983;101:817-22.

6 Tina LU, Lou MF, Dizio D, Calcagno PL. Alteration of collagen metabolism in hereditary nephritis. Pediatr Res
1979;13:774-9.

7 Kefalides NA. Structure and biosynthesis of basement membranes. International Review of Connective Tissue Research 1973;6:63-79.

8 Häusler J. Darstellung von cis und trans C3 substituierten Prolinverbindungen. Liebigs Annalen der Chemie 1981; 1073-91.

9 Lindblad WJ, Diegelmann RF. Quantitation of hydroxyproline isomers in acid hydrolysates by HPLC. Ann Biochem 1984;138:390-4.

10 Donike M. N-trifluoracetyl-o-trimethylsilyl-phenolalkylamine: Darstellung und massenspezifischer gaschromatographischer Nachweis. F Chromatogr 1985;103:91-6.

11 Vycudilik W, Lubec G. The determination of $3 \mathrm{OH}$-proline by gas chromatography and mass spectrometry. In: Lubec by gas chromatography and mass spectrometry. In: Lubec G, Campese V, eds. Advances

12 SAS Institute Inc. SAS user's guide: statistics. Cary NC: SAS Institute Inc, 1982.

13 Veltischev Y, Ignatova M, Anenko A, et al. Hereditary nephritis and hypoplastic dysplastic nephropathy: hydroxynephritis and hypoplastic dysplastic nephropathy: hydroxy-
lysine glycoside excretion and the glomerular basement lysine glycoside excretion and the glomerular
membrane. Int $\mathcal{F}$ Pediatr Nephrol 1983;4:149-54

14 Schröder CH, Monnens LAH, van Lith HMA, Trijbels JMF, Veerkamp JH, Langveld JPM. The urinary excretion of hydroxylysine and its glycosides in Alport's syndrome and several other glomerulopathies. Nephron 1986;44: 103-7.

15 Borel JP, Chanard J, Randoux A. Determination of 3 hydroxyproline in urine. In: Lubec G, ed. Methods in nephrology. London: Libbey, 1983.

16 Bellon G, Berg R, Chastang F, Malgras A, Borel JP. Separation and evaluation of the cis and trans isomers of hydroxytion and evaluation of the cis and trans is.

17 Lubec G, Blazar E, Weissenbacher G, Syre C. Urinary excretion of glomerular basement membrane antigens in Alport's syndrome. Arch Dis Child 1978;53:401-6.

\section{Corrosive injury to the oesophagus}

Early oesophagoscopy to assess the presence or extent of damage is now routine after caustic ingestion. ${ }^{1}$ There has been doubt about the effectiveness of steroid drugs given to prevent oesophageal stenosis from the more severe injuries.

A trial done in Washington DC (Anderson et al, New England Fournal of Medicine 1990;323:637-40) has shown no benefit from steroids given within 24 hours of the ingestion. A total of 131 children were assigned randomly to receive no treatment or steroids, initially given as intravenous prednisolone and later as oral prednisone for a total of five or six weeks. Ampicillin was given concurrently with the steroid.

Oesophageal stricture developed in $\mathbf{1 0}$ of $\mathbf{3 1}$ children in the steroid group and in 11 of 29 untreated. Four steroid treated children and seven controls needed oesophageal replacement. Neither difference was statistically significant.

ARCHIVIST

1 Lovejoy FH. Corrosive injury of the oesophagus in children. N Engl $\mathcal{F}$ Med 1990; 323:668-70. 